\title{
CONFINED FLUIDIZATION OF FINES IN FIXED BED OF COARSE PARTICLES
}

\author{
Bronisław Buczek, Piotr Zabierowski* \\ AGH-University of Science and Technology, al. Mickiewicza 30, 30059 Cracow, Poland
}

\begin{abstract}
Experiments on a confined fluidized bed system with various shapes of particles have been presented in the paper. Its influence on hydrodynamic properties in the whole range of gas velocity has been analysed. Relations allowing calculation of the Richardson-Zaki-type equation coefficients, including description of inter-particle void and gas pressure drop in such systems have been determined. Necessary condition for confined fluidization of non-spherical coarse particles has also been determined.
\end{abstract}

Keywords: fluidization, confined fluidized bed, hydrodynamic

\section{INTRODUCTION}

Confined fluidized bed system is composed of two components: a fixed bed built of coarse elements and fines fluidizing within free spaces. Such a structure of the bed increases the efficiency of homogeneous and heterogeneous processes, in comparison to conventional beds (Gabor, 1966; Jasiński et al., 2007; Roes and Van Swaaij, 1979; Xianghai et al., 2004; Zabierowski and Buczek, 2014). A variety of the system applications calls for determination of not only influence of fine and coarsegrained materials on the bed hydrodynamics but also effect of the development of external particle surface (Buczek and Zabierowski, 2015).

The present studies were focused on this problem. Reports published so far neglected this factor as insignificant (Buczek and Zabierowski, 2001; Girimonte and Vivacqua, 2011; Michalski and Ziółkowski, 1999; Zabierowski, 2012). However, preliminary studies proved that it might have a significant impact on the relations between expansion and pressure drop (Buczek and Zabierowski, 2015).

\section{EXPERIMENTAL}

\subsection{Materials}

In the conducted experiments the fluidized bed composed of glass balls having three different diameters $\left(d_{f}\right)$, tapped bed porosity $\left(\varepsilon_{\mathrm{bt}}\right)$, tapped density $\left(\rho_{b t}\right)$ and aerated density $\left(\rho_{b a}\right)$ and approximate true density $\left(\rho_{p f}\right)$, determined with a Powder Characteristics Tester. Their characteristics are complemented by the values of sphericity $(\Phi)$ and minimum fluidization velocity in the fixed fluidized bed $\left(U_{m f}\right)$. 
Deposed fixed bed layer is composed of various materials, e.g. active carbon, glass balls (Ballotini), activated alumina, silica gel with similar diameter $\left(D_{p}\right)$, various true density $\left(\rho_{p}\right)$ and aerated density $\left(\rho_{b}\right)$ and fixed bed porosity $\left(\varepsilon_{p}\right)$. Characteristics of the materials listed in Tables 1 and 2 also include the symbols, description of shape and Geldart's group (Buczek and Geldart, 1986; Geldart, 1973).

Table 1. Properties of fluidized fines

\begin{tabular}{|c|c|c|c|c|c|c|c|c|}
\hline Material & $\begin{array}{c}\text { diameter } \\
d_{f, 1} 10^{-6} \mathrm{~m}\end{array}$ & $\begin{array}{c}\varepsilon_{b t} \\
\mathrm{~m}^{3} / \mathrm{m}^{3}\end{array}$ & $\begin{array}{c}\rho_{p f} \\
\mathrm{~kg} / \mathrm{m}^{3}\end{array}$ & $\begin{array}{c}\rho_{b a} \\
\mathrm{~kg} / \mathrm{m}^{3}\end{array}$ & $\rho_{b t} / \rho_{b a}$ & $\begin{array}{c}U_{m f} \\
\mathrm{~m} / \mathrm{s}\end{array}$ & $\begin{array}{c}\Phi \\
\mathrm{m}^{2} / \mathrm{m}^{2}\end{array}$ & $\begin{array}{c}\text { Geldart } \\
\text { group }\end{array}$ \\
\hline Ballotini (B1) & $55-100$ & 0.343 & 2738 & 1686 & 1.07 & 0.0058 & 0.99 & $\mathrm{~B}$ \\
\hline Ballotini (B2) & $150-180$ & 0.388 & 2563 & 1486 & 1.06 & 0.0145 & 0.99 & $\mathrm{~B}$ \\
\hline Ballotini (B3) & $290-420$ & 0.365 & 2825 & 1744 & 1.03 & 0.1620 & 0.99 & $\mathrm{~B}$ \\
\hline
\end{tabular}

Table 2. Properties of coarse particles

\begin{tabular}{|l|c|c|c|c|c|c|c|}
\hline \multicolumn{1}{|c|}{ Material (sign) } & $\begin{array}{c}\text { diameter } \\
D_{p}, 10^{-3} \mathrm{~m}\end{array}$ & $\begin{array}{c}\varepsilon_{p} \\
\mathrm{~m}^{3} / \mathrm{m}^{3}\end{array}$ & $\begin{array}{c}\rho_{p} \\
\mathrm{~kg} / \mathrm{m}^{3}\end{array}$ & $\begin{array}{c}\rho_{b} \\
\mathrm{~kg} / \mathrm{m}^{3}\end{array}$ & $\rho_{p} / \rho_{b}$ & shape & $\begin{array}{c}\text { Geldart } \\
\text { group }\end{array}$ \\
\hline Ballotini (B) & 6.0 & 0.406 & 3053 & 1814 & 1.68 & sphere & $\mathrm{D}$ \\
\hline Activated Alumina (Al) & $5.6-6.7$ & 0.413 & 1359 & 798 & 1.70 & sphere & $\mathrm{D}$ \\
\hline Silica Gel (SG) & $4-7$ & 0.422 & 1435 & 829 & 1.73 & irregular & $\mathrm{D}$ \\
\hline Activated Carbon (AC) & 6.0 & 0.503 & 1324 & 658 & 2.01 & cylinder & $\mathrm{D}$ \\
\hline
\end{tabular}

Combinations of fines particles and coarse-grained materials provided 12 systems of different properties, described with symbols marking their composition: fixed bed/fluidal particles (for example: $\mathrm{AC} / \mathrm{B} 1, \mathrm{~A} 1 / \mathrm{B} 2, \mathrm{SG} / \mathrm{B} 3, \mathrm{~B} / \mathrm{B} 1)$.

\subsection{Apparatus and experimental technique}

Hydrodynamic experiments were conducted in the system presented in Fig. 1.

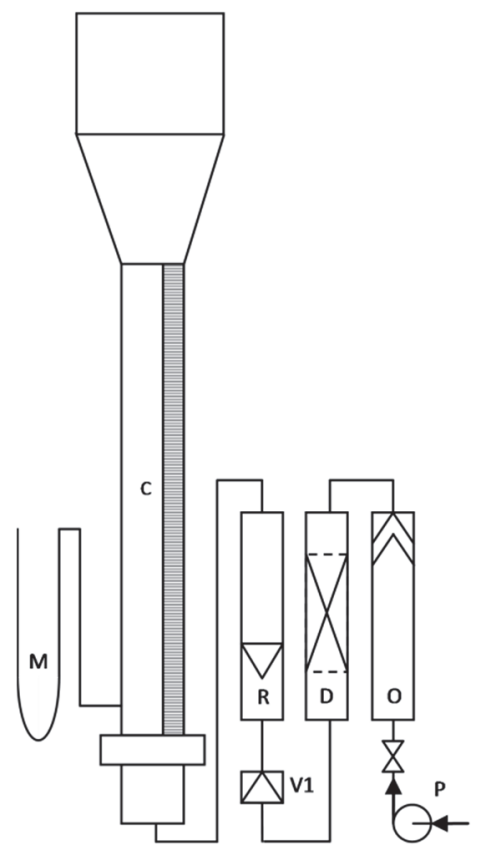

Fig. 1. Experimental equipment 
From the compressor $(\mathrm{P})$ air was directed into the fluidal column $(\mathrm{C})$ and then passed the oil separator $(\mathrm{O})$, the drier $(\mathrm{D})$, the reducer (V1), the rotameter (R) and the distributor of high-pressure drop (GD). The column of $0.1016 \mathrm{~m}$ diameter and height $0.96 \mathrm{~m}$ was made of PMMA glass. It was equipped with a scale measuring height of the bed components and a sounder used for measurement of the layer pressure drop connected with the water manometer (M). The sounder was placed $1 \mathrm{~mm}$ over the gas distributor.

Before the experiment, weighted mass of coarse particles was introduced into the column and as a result of vibration a fixed bed $0.68 \mathrm{~mm}$ high was formed. Then the pressure drop in the fixed bed $\left(\Delta P_{P}\right)$ with reference to the gas velocity $\left(U_{g}\right)$ was determined. A similar relation was determined for the confined fluidized bed after introduction to the fixed bed a $1 \mathrm{~kg}$ and then $2 \mathrm{~kg}$ portion of fine particles. In the experiments, the heights of fluidal layer during porosity growth and expansion of this phase up to reaching the top of the fixed bed were recorded.

Experimental cycles allowed determination of the following relation:

- pressure drop due to increase of the gas velocity in the fixed bed

$$
\frac{\Delta P_{P}}{H}=f\left(U_{g}\right)
$$

- analogous relation in the confined fluidized bed

$$
\frac{\Delta P_{\Sigma}}{H}=f\left(U_{g}\right)
$$

- relation between fluidized phase porosity change and gas velocity

$$
\varepsilon_{f}=1-\frac{1}{\varepsilon_{p}} \frac{m_{\sum d}}{\rho_{p f} H S}=f\left(U_{g}\right)
$$

Results obtained in systems AC/B1, AC/B2, AC/B3, B/B1, B/B2, B/B3, A1/B1, A1/B2, A1/B3, SG/B1, $\mathrm{SG} / \mathrm{B} 2, \mathrm{SG} / \mathrm{B} 3$ are shown in the form of diagrams. Minimum confined fluidization velocity $\left(U_{1}\right)$ was read from the diagram of relations (2) (as the point of beginning the gas pressure drop stabilization) and then compared with conventional $\left(U_{m f}\right)$. Experimental minimum fluidized phase porosity $\left(\varepsilon_{m f \text { exp }}\right)$ was read from the diagram of relations (3) and experimental coefficients $\left(n, \alpha=U_{2}\right)$ was determined from the fit with Richardson-Zaki type equation (Yang and Renken, 2003; Richardson and Zaki, 1954).

$$
U_{g}=\alpha \varepsilon_{f}^{n}
$$

Here $U_{2}$ is considered as entrainment velocity of fine particles for $\varepsilon_{f}=1$. Diagram (2) in all systems was correlated with Equation (5) defined by Michalski and Ziółkowsk (1999).

$$
\frac{\Delta P_{\Sigma}}{H\left(1-\varepsilon_{f}\right) \varepsilon_{p} \rho_{p f} g}=0.91+2.45(N-1)^{0.153}\left(\frac{D_{p}}{d_{f}}-11.2\right)^{-0.297}
$$

Unit pressure difference being the measure of contribution of the fines in flow resistances of confined fluidized bed was determined from relations (2) and (1).

$$
\frac{\Delta P_{d}}{H}=\frac{\Delta P_{\Sigma}}{H}-\frac{\Delta P_{P}}{H}=f\left(U_{g}\right)
$$




\section{EXPERIMENTAL RESULTS}

\subsection{Minimum of fluidization}

Before beginning of fluidization, all fines are deposed on elements of the fixed bed and they occupy a volume corresponding to $\varepsilon_{p}$ of the confined fluidized bed space. In this initial phase their density can be assumed as equal to $\rho_{b a}$. After initiation of the confined fluidised bed fluidization, only a part of the bed volume will be accessible for fluidal phase because a considerable fragment of the inter-particle space is still occupied by deposed fines. According to Buczek and Zabierowski (2015) their mass depends on motion resistances, which are proportional to the ratio $U_{1} / \varepsilon_{p} U_{m f}$. Assuming the mentioned mass participation of fines fluidizing in the bed as

$$
x_{d f}=\frac{m_{d f}}{m_{\Sigma d}}=\frac{\varepsilon_{p} U_{m f}}{U_{1}}
$$

and mass ratio of not fluidized fines in the bed (deposed on fixed bed particles)

$$
x_{d p}=\frac{m_{d p}}{m_{\Sigma d}}=1-x_{d f}
$$

we can calculate minimum mass ratio of fluidized fines in the bed inter-particle space at $U_{1}$.

$$
y_{d f \min }=\left(\frac{V_{d f}}{V_{\Sigma d}}\right)_{\min }=\left(1-\frac{V_{d p}}{V_{\Sigma d}}\right)_{\min }=1-\frac{\frac{m_{d p}}{\rho_{b a}}}{\frac{m_{\Sigma d}}{\rho_{b a}}}=x_{d f}
$$

After dividing the numerator and the denominator $y_{d f \min }$ by a volume of the total confined fluidized bed we can prove that the relation $U_{1} / \varepsilon_{p} U_{m f}$ (proportional to fluidal fines motion resistances) is equal to

$$
\frac{1}{x_{d f}}=\frac{\varepsilon_{p}}{\varepsilon_{p}-\varepsilon_{p} x_{d p}}=\frac{\varepsilon_{p}}{\varepsilon_{p r e l}}
$$

i.e. to the ratio of fixed bed porosity and real fixed bed porosity penetrable for fluidized fine particles.

A relation between the minimum fluidized phase porosity $\varepsilon_{m f \text { exp }}$ and growth of the ratio $\varepsilon_{p} / \varepsilon_{p}$ rel is shown in Fig. 2.

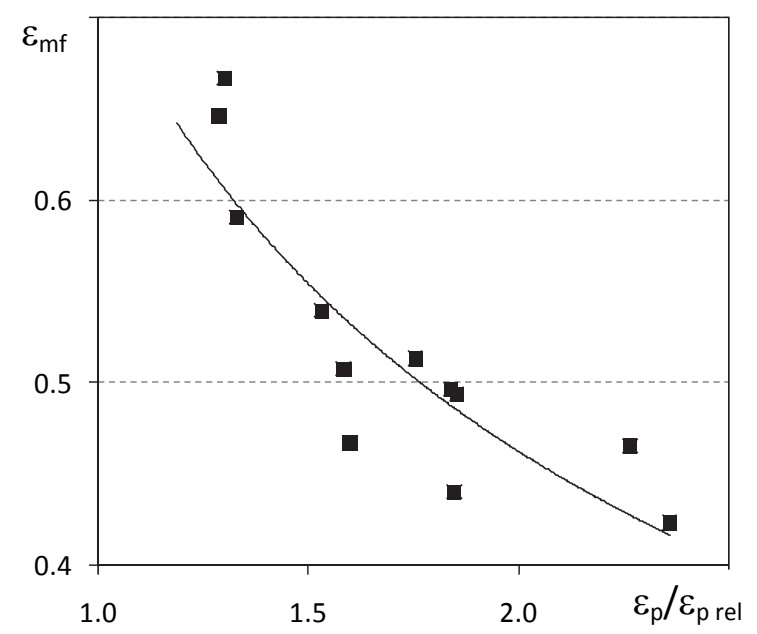

Fig. 2. Changes of $\varepsilon_{m f}$ vs. growth of $\varepsilon_{p} / \varepsilon_{p}$ rel in experimental systems 
As seen from Fig. 2, the systems in which the amount of fines deposed on fixed bed is the highest (high $\varepsilon_{p} / \varepsilon_{p}$ rel) are characterized with a low minimal bed porosity $\varepsilon_{m f}$. It results from the assumed procedure of $\varepsilon_{m f}$ calculation, where the total inter-particle volume is included in the fluidal phase volume (including that between fines deposed on the fixed bed). This calculation procedure (Mandal et al., 2011; Donsi et al., 1988) is proper in case of conventional fluidal systems, where non-fluidized particles are absent. However, in case of confined fluidized bed this procedure is improper, because it does not characterize porosity of fluidal phase only but the whole fines fluidizing and deposed on the fixed bed. Direct evidence comprises streams of lower density observed at velocity $U_{1}$, which are interpreted as channelling (Mandala et al., 2011). If an experimental value of $\varepsilon_{m f}$ exp $/ \varepsilon_{b a}$ depends on porosity of the fluidized and not fluidized fines (deposited on fixed bed) proportionally to their volume, it can be described as:

$$
\frac{\varepsilon_{m f \text { exp }}}{\varepsilon_{b a}}=\frac{\varepsilon_{b a} \frac{V_{d p}}{V_{\Sigma d}}+\varepsilon_{m f} \text { rel } \frac{V_{d f}}{V_{\Sigma d}}}{\varepsilon_{b a}}
$$

where:

$$
\begin{gathered}
y_{d p}=\frac{V_{d p}}{V_{\Sigma d}}=x_{d p} \frac{\rho_{m f \text { exp }}}{\rho_{b a}}=x_{d p} \frac{\left(1-\varepsilon_{m f \text { exp }}\right) \rho_{p f}}{\rho_{b a}} \\
y_{d f}=\frac{V_{d f}}{V_{\Sigma d}}=1-y_{d p}
\end{gathered}
$$

Substituting such expressed ratios $y_{d p}, y_{d f}$ from Eqs. (12) and (13) and $x_{d p}$ from Eqs. (8) and (10) to Eq. (11) we can calculate a dimensionless true porosity value in the fluidizing part of fines referring to their fluidized phase aerated porosity $\varepsilon_{m f \text { rel }} / \varepsilon_{b a}$

$$
y_{d f}=\frac{V_{d f}}{V_{\Sigma d}}=1-y_{d p}
$$

A more universal form of the relation between the minimum confined fluidized phase porosity and a measure of the motion resistances within the bed $\varepsilon_{p} / \varepsilon_{p}$ rel is shown in Fig. 3, where the ordinate axis comprises of a dimensionless value $\varepsilon_{m f} / \varepsilon_{b a}$. The true (Eq. (14)) and the experimental values of $\varepsilon_{m f} / \varepsilon_{b a}$ were also compared. Values of $\varepsilon_{m f \text { rel }} / \varepsilon_{b a}$ are up to $10 \%$ higher than those obtained in direct measurements within the range of high $\varepsilon_{p} / \varepsilon_{p}$ rel values.

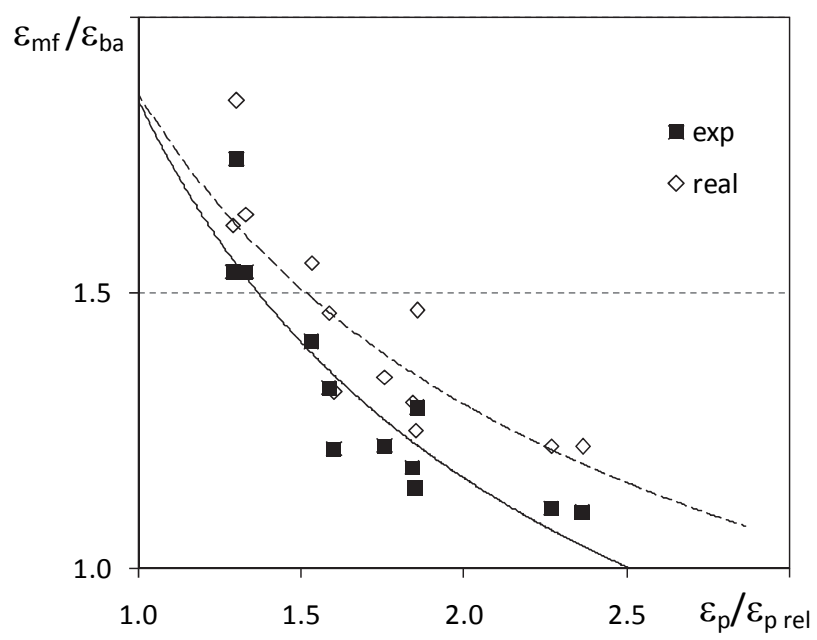

Fig. 3. Experimental and true value (14) of $\varepsilon_{m f} / \varepsilon_{b a}$ vs. growth of $\varepsilon_{p} / \varepsilon_{p}$ rel in tested systems 
As seen, experimental values comprise the whole range of variables having physical sense. In systems with no fluidization $\left(\varepsilon_{m f} / \varepsilon_{b a}=1\right)$, fines deposed on fixed bed occupy the whole inter-particle volume $\left(\varepsilon_{p}\right)$, and maximum value of $\varepsilon_{p} / \varepsilon_{p}$ rel is close to 2.5 . In systems where $\varepsilon_{p} / \varepsilon_{p}$ rel $=1$ all fines are fluidized (lack of fines deposed on fixed bed), minimum porosity is the highest and equal to the true value $\left(\varepsilon_{m f \text { exp }} / \varepsilon_{m f \text { real }}=1\right)$. This value corresponds to an analogue value in conventional fluidization. Experimental data for all systems are well represented by Equation (15) with a mean deviation of 5\%.

$$
\frac{\varepsilon_{m f}}{\varepsilon_{b a}}=1.845{\frac{\varepsilon_{p}}{\varepsilon_{p \text { rel }}}}^{-\frac{2}{3}}
$$

In various papers, the value of $d_{f} / D_{p}<0.096-0.414$ (Sutherland et al., 1963) is considered as a boundary condition fluidization of fine particles in a fixed bed. Difficulties related with fluidization of fines from A group Geldart's classification, where extensive development of external surface precludes obtaining uniform fluidization like in case of conventional fluidized bed (Donsi et al, 1990; Zabierowski, 2008), was also mentioned. Relations shown in Figs. 2 and 3 generally characterize the last restrictions of the confined fluidized bed existence, including influence of the fixed bed. As seen, fixed-fluidized systems, where confined fluidization is possible, should also satisfy condition (16):

$$
\frac{\varepsilon_{p}}{\varepsilon_{p \text { rel }}}<2.5
$$

This condition results from resistance to the movement of fines within the fixed bed (proportional to $\varepsilon_{p} / \varepsilon_{p}$ rel) - but not from geometrical restrictions, as in the case of the condition for $d_{f} / D_{p}$.

Then experiments have been conducted with sphere-shaped materials and other materials characterized with high porosity (Raschig and Pall rings, Berl saddle, cylinders) (Donsi et al., 1990; Gabor, 1966; Roes and Van Swaaij, 1979). For both material types, the limitation (16) does not exist. It is seen in Fig. 4 , where relation $\varepsilon_{p} / \varepsilon_{p}$ rel vs. fraction of $D_{p} / d_{f}$ in systems $\mathrm{AC} / \mathrm{B} 1 \div \mathrm{B} 3, \mathrm{~B} / \mathrm{B} 1 \div \mathrm{B} 3, \mathrm{~A} 1 / \mathrm{B} 1 \div \mathrm{B} 3$, $\mathrm{SG} / \mathrm{B} 1 \div \mathrm{B} 3$ is presented.

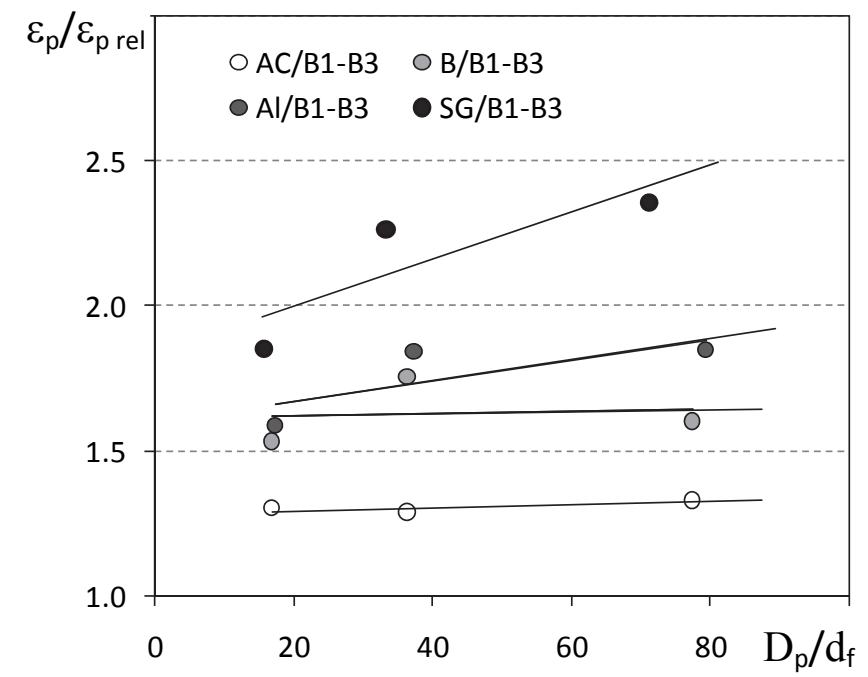

Fig. 4. Influence of fraction $D_{p} / d_{f}$ on fluidization resistance $\varepsilon_{p} / \varepsilon_{p}$ rel in systems $\mathrm{AC} / \mathrm{B} 1 \div \mathrm{B} 3, \mathrm{~B} / \mathrm{B} 1 \div \mathrm{B} 3, \mathrm{Al} / \mathrm{B} 1 \div \mathrm{B} 3, \mathrm{SG} / \mathrm{B} 1 \div \mathrm{B} 3$

In case of spherical $(\mathrm{B} / \mathrm{B} 1 \div \mathrm{B} 3)$ and high porosity systems $(\mathrm{AC} / \mathrm{B} 1 \div \mathrm{B} 3)$, the value of $\varepsilon_{p} / \varepsilon_{p}$ rel is not dependent on $D_{p} / d_{f}$. Whereas, in case of non-spherical and low porosity systems $(\mathrm{A} 1 / \mathrm{B} 1 \div \mathrm{B} 3$, $\mathrm{SG} / \mathrm{B} 1 \div \mathrm{B} 3)$, an increase of $\varepsilon_{p} / \varepsilon_{p}$ rel proportional to diameter fraction and development of the system surface was observed. Further decrease of the diameter of fines in the system G/B1 $\div$ B3 could lead to 
reaching the boundary value $\varepsilon_{p} / \varepsilon_{p}$ rel $=2.5$. In case of such systems the confined fluidization is impossible because the condition (16) is not satisfied.

\subsection{Fines entrainment velocity}

The upper boundary of the gas velocity regime - fines entrainment velocity $U_{2}$, according to the described methodology (apparatus and experimental technique, relation (4)), was determined via extrapolation of the experimental Richardson Zaki type relations to $\varepsilon_{f}=1$ (the highest porosity in the confined fluidized bed). It corresponds to the total removal (by gas) of fines from inter-particle space of the fixed bed.

Experimental values proved lack of dependence of $U_{2}$ on $\varepsilon_{\mathrm{p}} / \mathcal{E}_{\mathrm{p}}$ rel. It is an evidence of negligible influence of the analysed interactions of fluidal-fixed particles on the system structure within low densities range of the fluidal phase $\left(\varepsilon_{f} \approx 1\right)$. Experimental gas velocities in-between fixed particles $U_{2} / \varepsilon_{\mathrm{p}}$ corresponding to fines free falling velocity $U_{0}$, depend on the criterion number $\mathrm{Ar}-\mathrm{a}$ measure of friction and gravity forces in a fluid.

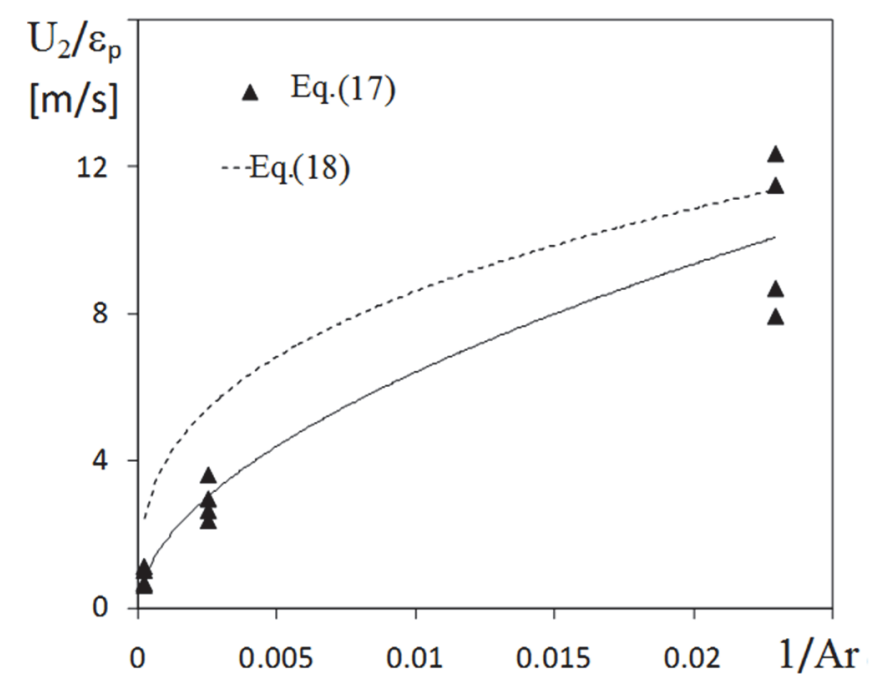

Fig. 5. Velocity $U_{2}$ vs. 1/Ar growth in experimental systems

Experimental results in all the systems $\mathrm{AC} / \mathrm{B} 1 \div \mathrm{B} 3, \mathrm{~B} / \mathrm{B} 1 \div \mathrm{B} 3, \mathrm{~A} 1 / \mathrm{B} 1 \div \mathrm{B} 3, \mathrm{SG} / \mathrm{B} 1 \div \mathrm{B} 3$ are well matched to Equation (17) with a mean deviation of $20 \%$.

$$
\frac{U_{2}}{\varepsilon_{p} U_{0}}=78 \mathrm{Ar}^{-\frac{2}{3}}
$$

It is close to Eq. (18) (Fig. 5 dotted line) proposed by Michalski and Ziółkowski (1999).

$$
\frac{U_{2}}{\varepsilon_{p} U_{0}}=26.58 \mathrm{Ar}^{-\frac{1}{3}}
$$

In the mentioned work $U_{2}$ was calculated on the basis of pressure drop comparison in fixed bed and in confined fluidized bed, respectively. Such determined fines entrainment velocities are higher. The differences between both functions (17) and (18) result probably from various $U_{2}$ calculation methods, although their changes vs. $1 / \mathrm{Ar}$ are similar.

The method used in this paper was system hydrodynamics analysis, based on Equation (4). In this case, the $U_{2}$ values better to calculate from the Eq. (17). 


\subsection{Bed expansion}

Experimental data for $\varepsilon_{f}$ for all systems are well represented by the Richardson-Zaki type Equation (4) with experimental values of $n$, and $\alpha=U_{2}$. The mean deviation in the tested systems is equal $10.7 \%$ (Table 3).

Table 3. Parameters of Richardson-Zaki type Equations (4) in the studied systems

\begin{tabular}{|l|c|c|c|c|c|c|c|c|}
\hline System & $\begin{array}{c}\varepsilon_{p} \\
\mathrm{~m}^{3} / \mathrm{m}^{3}\end{array}$ & $\begin{array}{c}\varepsilon_{m f \text { exp }} \\
\mathrm{m}^{3} / \mathrm{m}^{3}\end{array}$ & $\begin{array}{c}U_{m f} \\
\mathrm{~m} / \mathrm{s}\end{array}$ & $\begin{array}{c}U_{1} \\
\mathrm{~m} / \mathrm{s}\end{array}$ & $\varepsilon_{p} / \varepsilon_{\mathrm{p} \text { rel }}$ & $\begin{array}{c}U_{2} \\
\mathrm{~m} / \mathrm{s}\end{array}$ & $n$ & $\begin{array}{c}\text { deviation } \\
\text { Rich.Zaki \% }\end{array}$ \\
\hline $\mathrm{AC} / \mathrm{B} 1$ & 0.503 & 0.590 & 0.0058 & 0.0039 & 1.33 & 2.844 & 12.282 & 14.5 \\
\hline $\mathrm{AC} / \mathrm{B} 2$ & 0.503 & 0.646 & 0.0145 & 0.0094 & 1.29 & 1.880 & 12.062 & 9.5 \\
\hline $\mathrm{AC} / \mathrm{B} 3$ & 0.503 & 0.667 & 0.1620 & 0.1061 & 1.30 & 0.814 & 5.469 & 6.7 \\
\hline $\mathrm{B} / \mathrm{B} 1$ & 0.406 & 0.467 & 0.0058 & 0.0038 & 1.60 & 2.136 & 7.816 & 17.1 \\
\hline $\mathrm{B} / \mathrm{B} 2$ & 0.406 & 0.513 & 0.0145 & 0.0103 & 1.76 & 1.242 & 7.169 & 7.5 \\
\hline $\mathrm{B} / \mathrm{B} 3$ & 0.406 & 0.540 & 0.1620 & 0.1008 & 1.53 & 1.098 & 3.761 & 3.3 \\
\hline $\mathrm{Al} / \mathrm{B} 1$ & 0.413 & 0.440 & 0.0058 & 0.0044 & 1.85 & 1.642 & 7.106 & 27.6 \\
\hline $\mathrm{Al} / \mathrm{B} 2$ & 0.413 & 0.496 & 0.0145 & 0.0110 & 1.84 & 1.128 & 6.572 & 9.1 \\
\hline $\mathrm{Al} / \mathrm{B} 3$ & 0.413 & 0.508 & 0.1620 & 0.1061 & 1.59 & 1.228 & 3.665 & 2.6 \\
\hline $\mathrm{SG} / \mathrm{B} 1$ & 0.422 & 0.423 & 0.0058 & 0.0058 & 2.36 & 1.531 & 6.340 & 11.4 \\
\hline $\mathrm{SG} / \mathrm{B} 2$ & 0.422 & 0.465 & 0.0145 & 0.0139 & 2.27 & 1.034 & 5.650 & 13.1 \\
\hline $\mathrm{SG} / \mathrm{B} 3$ & 0.422 & 0.494 & 0.1620 & 0.1269 & 1.86 & 0.747 & 2.545 & 5.7 \\
\hline
\end{tabular}

The values of the coefficient $n$ are within a range from 2 to 12 , which is considerably broader than that found by Capes and McIlhinney (1968), but they are related with systems of lower packing porosity. However, the lower value of this coefficient is similar. Experimental values of the parameter $n$ for all systems are well approximated with Equation (19):

$$
n=\log _{\varepsilon_{m f \exp }} \frac{U_{1}}{U_{2}}-0.794
$$

The constant -0.794 in this Equation was compared with the expression:

$$
-0.794=\log _{\varepsilon_{m f \text { exp }}} b
$$

and a value of $b$ calculated for the all experimental systems was then compared with $\varepsilon_{p} / \varepsilon_{p}$ rel (Fig. 6).

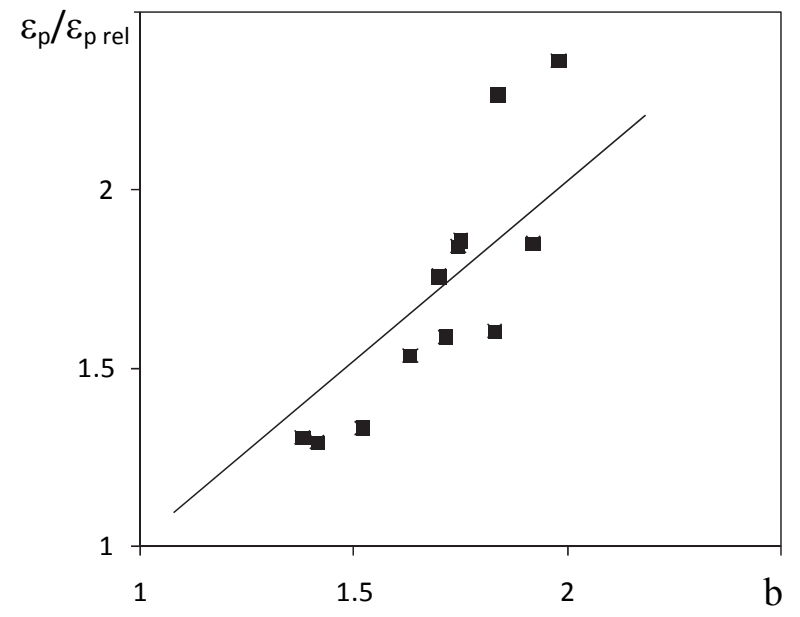

Fig. 6. Constant $b$ (Eq. (20)) in experimental systems vs. $\varepsilon_{p} / \varepsilon_{p}$ rel growth nozzle diameters

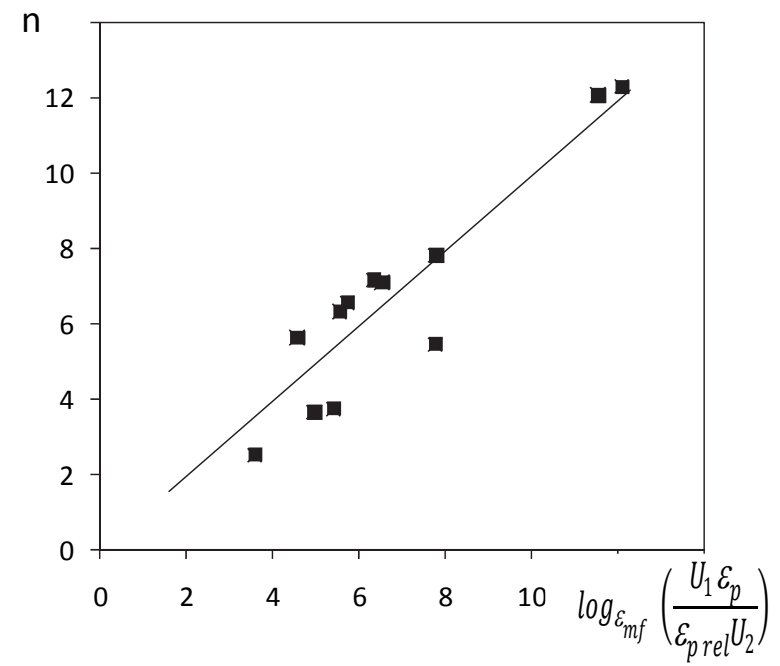

Fig. 7. Values of coefficients $n(4)$ in experimental systems and from Equation (21) 
As seen from Fig. 6, the value of $b$ can be identified with porosity ratio $\varepsilon_{p} / \varepsilon_{p}$ rel characteristic for the experimental system. Thus Equation (19) was rearranged into (21):

$$
n=\log _{\varepsilon_{m f}} \frac{U_{1}}{U_{2}} \frac{\varepsilon_{p}}{\varepsilon_{\text {prel }}}
$$

In the tested systems, Equation (21) satisfactorily matches experimental values of $n$ with the mean deviation of $18.2 \%$. The term $U_{1} \varepsilon_{p} / U_{2} \varepsilon_{p}$ rel is a true gas velocity ratio (within fixed inter-particle spaces) at the borders of the gas velocity regime $U_{1} / \varepsilon_{p}$ rel and $U_{2} / \varepsilon_{p}$. Equation (21) and proper fit to the experimental values of coefficients n (Fig. 7), proves the correctness of the presented interpretation of the $U_{1} / \varepsilon_{p} U_{m f}$ expression (Eqs. 7-10).

We can also suppose that the inter-particle space available for the particles of fluidal phase in a given system increases from $\varepsilon_{p}$ rel to $\varepsilon_{p}$ with the bed porosity $\varepsilon_{f}$ and gas velocity increases as a result of Equation (21).

\subsection{Bed pressure drop}

In Figs. 8 and 9 we can compare a unit pressure drop within the confined fluidized bed $\Delta P_{\Sigma} / H$ Eq.(2) and its contribution into this total value of individual components of this bed: fluidized fines $\left(X_{f}\right)$ and those deposed on the fixed bed $\left(X_{p}\right)$.

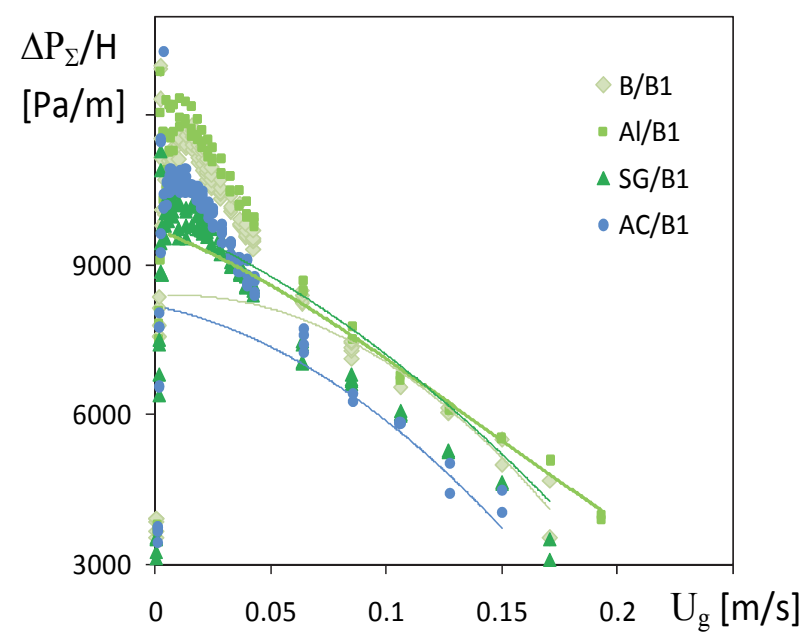

Fig. 8. Example of changes in $\Delta P_{\Sigma} / H$ (Eq.(2)) and Equation (5); systems B/B1, AC/B1, A1/B1, SG/B1

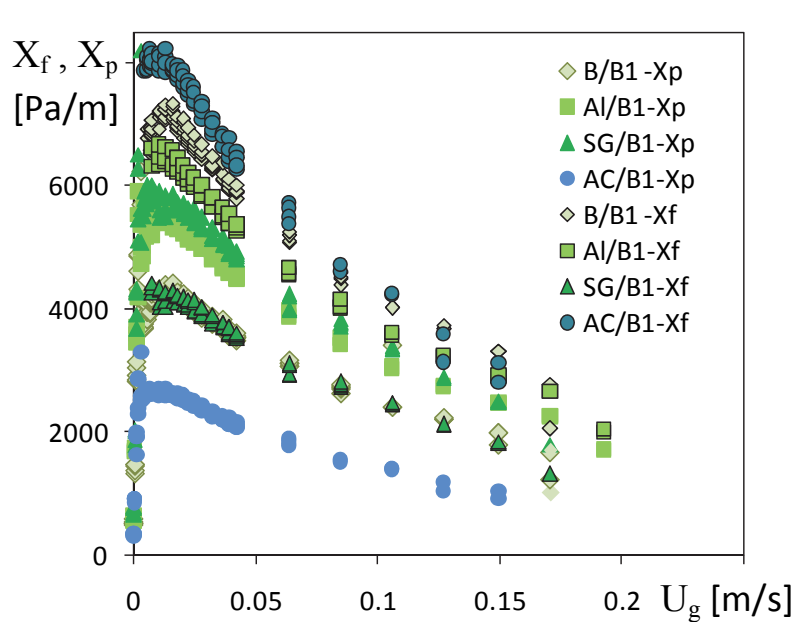

Fig. 9. Pressure drop within bed components $X_{f}$ (Eq. (22)) and $X_{p}$ (Eq. (23)); systems B/B1, AC/B1, A1/B1, SG/B1

Values $X_{f}$ and $X_{p}$ were calculated from the experimentally determined pressures $\Delta P_{d} / H$ and $x_{d f}$ and $x_{d p}$ (Eqs. 7 and 8) like described by Buczek and Zabierowski (2015):

$$
\begin{aligned}
& X_{f}=\frac{\Delta P_{d f}}{H}=x_{d f} \frac{\Delta P_{d}}{H} \\
& X_{p}=\frac{\Delta P_{d p}}{H}=x_{d p} \frac{\Delta P_{d}}{H}
\end{aligned}
$$

Figure 9 explains reasons for the diversification experimental values of $\Delta P_{\Sigma} / H$ in the systems with similar particle sizes, which have been compared with Equation 5 in Figure 8. In case of systems with 
well developed surface of the fixed bed A1/B1, SG/B1 the pressure drop of deposed (not fluidized) fines $X_{p}$ (Fig. 9) comprises a considerable part of the total pressure drop, in contrary to systems with low fixed bed resistances B/B1, AC/B1. As seen in Fig. 9, in case of the systems B/B1, AC/B1 the highest pressure drop occurs within fluidizing fines $\left(X_{f}\right)$. It is the main reason of relatively high total values of $\Delta P_{\Sigma} / H$ (Fig. 8) within these systems (in spite of low $X_{p}$ ). Similar observations could be made for other systems, not shown in Figs. 8 and 9.

The fact that the fraction $\Delta P_{d} / \Delta P_{\max }$ is constant in a given fluidal-fixed particle system is a common feature for all experimental systems. It compares experimental pressure drop in the bed $\Delta P_{d} / H$ with values corresponding to complete fluidization of all fines $\Delta P_{\max } / H$ (like in case of conventional fluidization):

$$
\frac{\Delta P_{d}}{\Delta P_{\max }}=\frac{\Delta P_{d}}{H} \frac{1}{\left(1-\varepsilon_{f}\right) \rho_{p f} g}
$$

This value characteristic for experimental systems can be observed in Fig. 10.
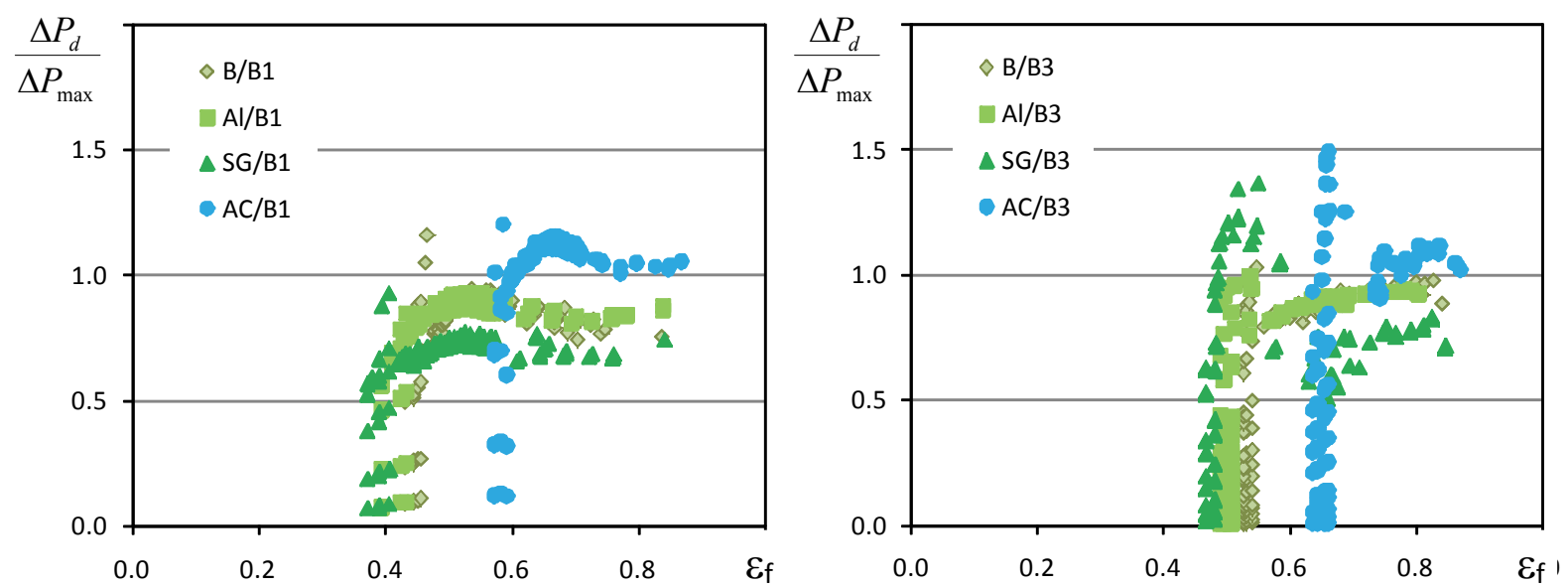

Fig. 10. Values of $\Delta P_{d} / \Delta P_{\max }(24)$ vs. growth of $\varepsilon_{\mathrm{f}}$ in fine-grained systems: a) B1, b) B3

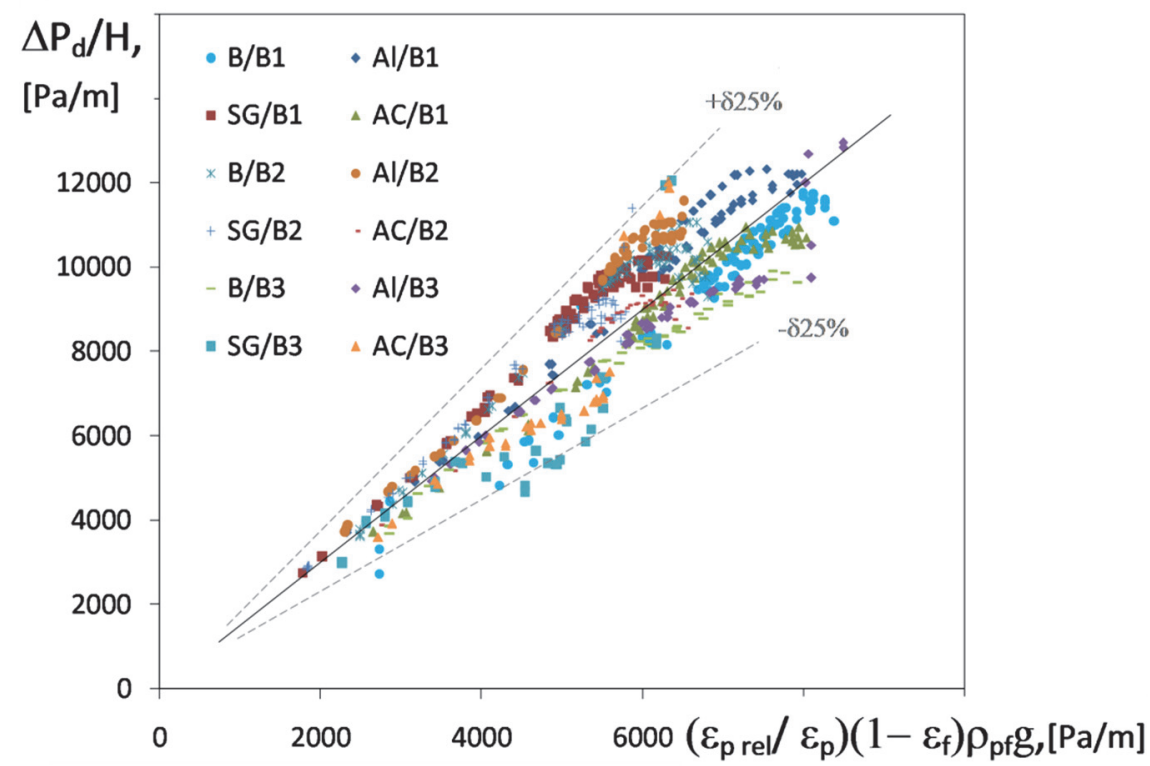

Fig. 11. Values $\Delta \mathrm{P}_{\mathrm{d}} / \mathrm{H}$ in experimental systems, including Equation (25)

In Fig. 11, pressure drop in the confined fluidized system can be described with the mean deviation of $8.9 \%(25)$ 
Stabilization of $\Delta P_{d} / \Delta P_{\max }$ in the range of $\varepsilon_{f}>\varepsilon_{m f}$ observed in all systems (Fig. 10; behind the maximum on the curves), proves typical, constant proportion of fine particles fluidized and deposed on the fixed bed. It confirms rightness of the pressure measurement methodology (Eqs. (22) and (23)) $\left(x_{d f}=\right.$ const, $x_{d p}=$ const $)$. Minor deviations are seen in the initial fragment of curves, where channelling phenomenon occurs. The highest values of $\Delta P_{d} / \Delta P_{\max }$ are observed within systems of the lowest resistance to particle motion and the highest amount of fluidizing fines (high $x_{d f}$ ).

The experimental values of $\Delta P_{d} / H$ were approximated by the expression, in which $x_{d f}$ is a ratio of fluidized fines and $\Delta P_{\max } / H=\left(1-\varepsilon_{f}\right) \rho_{p f} g$ is a measure of the maximum unit pressure drop (shown in a parity plot, Fig. 11).

$$
\frac{\Delta P_{d}}{H}=A x_{d f} \frac{\Delta P_{\max }}{H}=1.52 \frac{\varepsilon_{p r e l}}{\varepsilon_{p}}\left(1-\varepsilon_{f}\right) \rho_{p f} g
$$

In this case, the constant is a measure of increment of the total pressure drop with reference to the values in fluidal bed component.

\section{SUMMARY AND CONCLUSIONS}

- It has been proved that the experimentally determined ratio of confined and conventional minimum fluidization velocities $U_{1} / \varepsilon_{p} U_{m f}$ is a reliable measure of the motion resistances for variously-shaped fluidal particles. Its value can be used to calculate the basic hydrodynamic parameters of a confined fluidised bed, as well as minimum porosity $\varepsilon_{m f}$ Eq. (15), coefficient $n$ Eq. (21) of the Richardson Zaki type equation and the bed pressure drop $\Delta P_{d} / H$, Eq. (25).

- The velocitie ratio in Eq. (10) is equal to the minimum ratio of the fixed bed porosity and the real fixed bed porosity that is penetrable for fluidized fine particles $\varepsilon_{p \text { rel }} / \varepsilon_{p}$. From the bed pressure drop curves (Fig. 10), the porosity limitation $\varepsilon_{p}$ to $\varepsilon_{p}$ rel is a typical feature of this bed because of the constant amount of not fluidized fines (deposed on the fixed bed) characteristic for a given system. It was also confirmed by other authors (Donsi et al, 1990).

- Over experimental porosity range $\varepsilon_{f}>\left(\varepsilon_{m f} \div 0.85\right)$, particles are gradually lifted up from the fixed bed, up to the velocity $U_{2}$. It is suggested by the form of Equation (21) and coefficient $n$ in the bed expansion Eq. (4), as well as the lack of correlation between the velocity $U_{2}$ and the ratio $\varepsilon_{p \text { rel }} / \varepsilon_{p}$. This range of high porosities is characterized with a number of different features described by Zabierowski (2008; 2009; 2012) and Buczek and Zabierowski (2001). Eq. (17) can be used to calculate the entrainment velocity of fines $U_{2}$, equal to the coefficient $\alpha$ in a twoparametric bed expansion correlation (Eq. 4), which was also formulated in the paper.

- As results from the experiments, the confined fluidized systems in spite of geometrical condition $d_{f} / D_{p}<0.096$ (Sutherland et al., 1963) should also satisfy the formulated condition $\varepsilon_{p} / \varepsilon_{p}$ rel $<2.5$ (cf. Eq. (16)). It occurs only in systems with non-spherical particles, where the increase of $\varepsilon_{p} / \varepsilon_{p}$ rel proportional to diameter fraction and development of the system surface was observed.

The authors are grateful for financial support of the paper (Project No 11.11.210.244 AGH).

\section{SYMBOLS}

$\begin{array}{ll}b & \text { parameter in Equation (20) } \\ d_{f}, D_{p} & \text { average diameter of fine particles, fixed particles, } \mathrm{m} \\ g & \text { gravitational acceleration, } \mathrm{m} / \mathrm{s}^{2} \\ m_{d f} & \text { mass of fluidized fines, } \mathrm{kg}\end{array}$




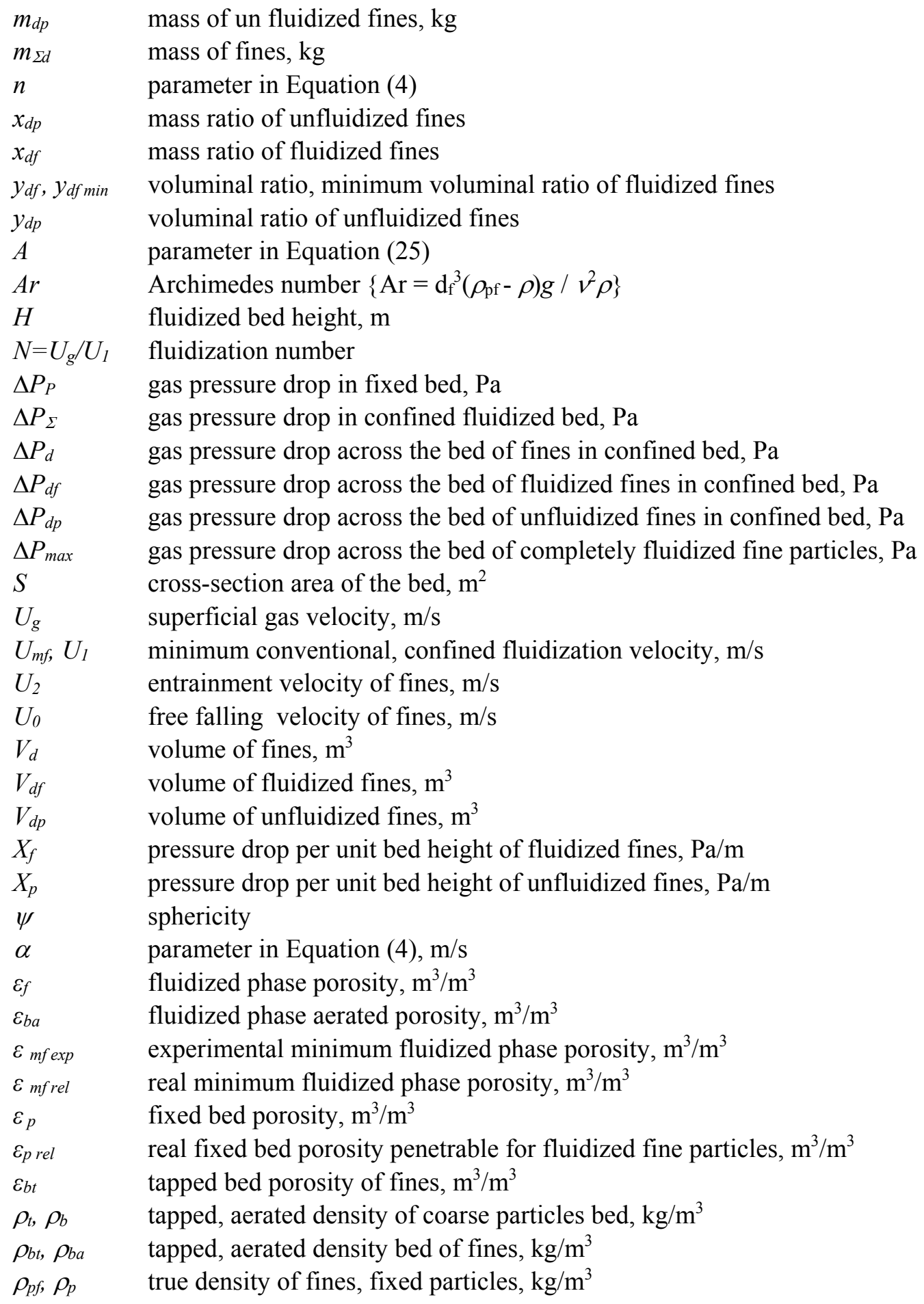

\section{REFERENCES}

Buczek B., Geldart D., 1986. Determination of the density of porous particles using very fine dense powders. Powder Technol., 45, 173-176. DOI: 10.1016/0032-5910(66)80010-4.

Buczek B., Zabierowski P., 2001. Removal of moisture by adsorption in confined fluidized bed. Chem. Process Eng., 22, 731-737.

Buczek B., Zabierowski P., 2015. Hydrodynamics of confined fluidization in a stationary bed with various particle shape. Przem. Chem., 11, 1977-1981. DOI: 10.15199/62.2015.10.15.

Capes C.E., McIlhinney A.E., 1968. The pseudoparticulate expansion of screen-packed gas fluidized beds. AIChE J., 14, 917-922. DOI: 10.1002/aic.690140617. 
Donsi G., Ferrari G., Formisani B., 1988. On the segregation mechanism of percolating fines in coarse particle fluidized beds. Powder Technol., 55, 153-158. DOI: 10.1016/0032-5910(88)80098-6.

Donsi G., Ferrari G., Formisani B., Longo G., 1990. Confined fluidization of fine particles: Model and experimental description. Powder Technol., 61, 75-85. DOI: 10.1016/0032-5910(90)80068-A.

Gabor J.D., 1966. Fluidized-packed beds. Chem. Eng. Progr., Symp. Ser. 62, 62, 32-41.

Geldart D., 1973. Types of gas fluidization. Powder Technol., 7, 285-292. DOI: 10.1016/0032-5910(73)80037-3.

Girimonte R., Vivacqua V., 2011. The expansion process of particle beds fluidized in the voids of a packing of coarse spheres. Powder Technol., 213, 63-69. DOI: 10.1016/j.powtec.2011.07.006.

Jasiński J., Mendzik K., Tatar M., Szota M., 2007. Microstructure and properties of titanium wire after oxidation in fluidized bed. Hutnik, 1-2, 32-34.

Mandal D., Sathiyamoorthyb D., Khakharc D.V., 2011. Fluidization characteristics of lithium-titanate in gas-solid fluidized bed. Fusion Eng. Des., 86, 393-398. DOI: 10.1016/j.fusengdes.2011.03.062.

Michalski J.A., Ziółkowski, D., 1999. Aerodynamic characteristics of an organized fluidized system. Chem. Proc. Eng., 20, 89-108.

Richardson J.F., Zaki W.N., 1954. Sedimentation and fluidization. Chem. Eng. Res. Des., 32, 35-52. DOI: 10.1016/S0263-8762(97)80006-8.

Roes A.W.M., Van Swaaij W.P.M., 1979. Hydrodynamic behaviour of a gas-solid counter-current packed column at trickle flow. Chem. Eng. J., 17, 81-89. DOI: 10.1016/0300-9467(79)85001-7.

Sutherland I.P., Vassilatos G., Kubota H., Osberg G.L., 1963. The effect of packing on a fluidized bed. AIChE J., 9, 437-441. DOI: 10.1002/aic.690090406.

Xianghai M., Chunming X., Jinsen G., Qian Z., 2004. Effect of catalyst to oil weight ratio on gaseous product distribution during heavy oil catalytic pyrolysis. Chem. Eng. Proc., 43, 965-970. DOI: 10.1016/j.cep.2003.09.003.

Yang J., Renken A., 2003. A generalized correlation for equilibrium of forces in liquid-solid fluidized beds. Chem. Eng. J., 92, 7-14. DOI: 10.1016/S1385-8947(02)00084-0.

Zabierowski P., 2008. Heat transfer of the adsorption process in a confined fluidized bed. Chem. Proc. Eng., 29, 191-200.

Zabierowski P., 2009. Mass transfer in the adsorption process of water vapour in a confined fluidized bed. Chem. Process Eng., 30, 389-402.

Zabierowski P., 2012. Confined fluidized bed porosity in the light of bubbling-bed models. Chem. Process Eng., 33, 431-444. DOI: 10.2478/v10176-012-0037-7.

Zabierowski P., Buczek B., 2014. Confined fluidization in technique, technology and the adsorber constructions. Przem. Chem., 11, 1974. DOI: 10.12916/przemchem.2014.1974.

Received 03 June 2016

Received in revised form 10 November 2016

Accepted 11 November 2016 